бюджетное образовательное учреждение высшего профессионального образования "Новосибирский государственный технический университет"- № 2014117408/28; заявл. 29.04.2014; опубл. 10.10.2015, Бюл. № 28. - 6 с. : ил.

8. Пат. 131496U1 Российская Федерация, МПК7 G 01 R 23/16. Анализатор гармоник [Текст] / Аравенков А.А., Пасынков Ю.А.; заявитель и патентообладатель Федеральное государственное бюджетное образовательное учреждение высшего профессионального образования "Новосибирский государственный технический университет"- №. 2012118134/28; заявл. 03.05.2012; опубл. 20.08.2013, Бюл. № 23. - 7 с. : ил.

\title{
Кулагин Д.Ю., Епишкина М.А. \\ Проектирование блока управления автоматизированного рабочего места технологической тренировки систем связи на основе УКВ радиостанций
}

Рязанский Государственньй Радиотехнический Университет (РГРТУ)

(Россия, Рязань)

doi:10.18411/spc-22-02-2018-03

idsp: 000001:spc-22-02-2018-03

Аннотация

Рассмотрены основные принципы и методы выявления потенциально ненадежных изделий, разработана структурная и функциональная схема блока управления автоматизированного рабочего места технологической тренировки приемопередатчика, входящего в состав системы УКВ связи.

Ключевые слова: приемопередатчик, технологическая тренировка, рабочие места, АРМ, блок управления.

\section{Annotation}

The basic principles and methods of identification of potentially unreliable products are considered, the structural and functional scheme of the control unit of the automated workplace of technological training of the transceiver which is a part of the VHF communication system is developed.

Keywords: transceiver, technological training, workplaces, arm, control unit.

В современных условиях процесс производства становится все более сложным, с каждым днем предъявляется все больше требований к технике, ее наличию на предприятиях и другим моментам, существенно ускоряющим производственную деятельность. Недостаточные возможности человеческих ресурсов, их низкая скорость работы вынуждают искать более качественные способы для повышения эффективности деятельности предприятий самых различных отраслей.

Внедрение полуавтоматической и автоматической испытательной аппаратуры и связанное с этим изменение технологического процесса позволят значительно повысить производительность труда, качество выполняемых работ, безопасность производственного процесса в целом.

Центральным узлом передачи и приема информации в любой системе связи является приемопередатчик.

Для повышения качества выпускаемых предприятием устройств, в частности приемопередатчиков, на предприятии изготовителе выпускаемые изделия подвергаются различным видам технологической тренировки.

Под технологической тренировкой (ТТ) понимается многократная проверка надежности действия приемопередающей аппаратуры при воздействии различных факторов.

В процессе производства $100 \%$ изделий проходят следующие этапы ТT: начальный прогон в нормальных условиях, тренировка при вибровоздействии, тренировка на холодоустойчивость, тренировка на теплоустойчивость, завершающий прогон в нормальных условиях[1]. 
Основными контролируемыми параметрами приемопередатчиков при ТT являются: выходная мощность, девиация, нестабильность частоты, чувствительность, нелинейные искажения.

Именно в процессе технологической тренировки происходит отсев изделий, имеющих дефектные комплектующие и возможный технологический брак при сборке, что значительно повышает надежность выпускаемых изделий и резко снижает вероятность их отказа в процессе эксплуатации.

Процесс технологической тренировки достаточно длительный, трудоёмкий, поэтому чтобы потренировать большое количество изделий создаются различные рабочие места комплексной проверки изделий.

В настоящее время тренировка проходит на ручном рабочем месте, структурная схема которого представлена на рис.1.

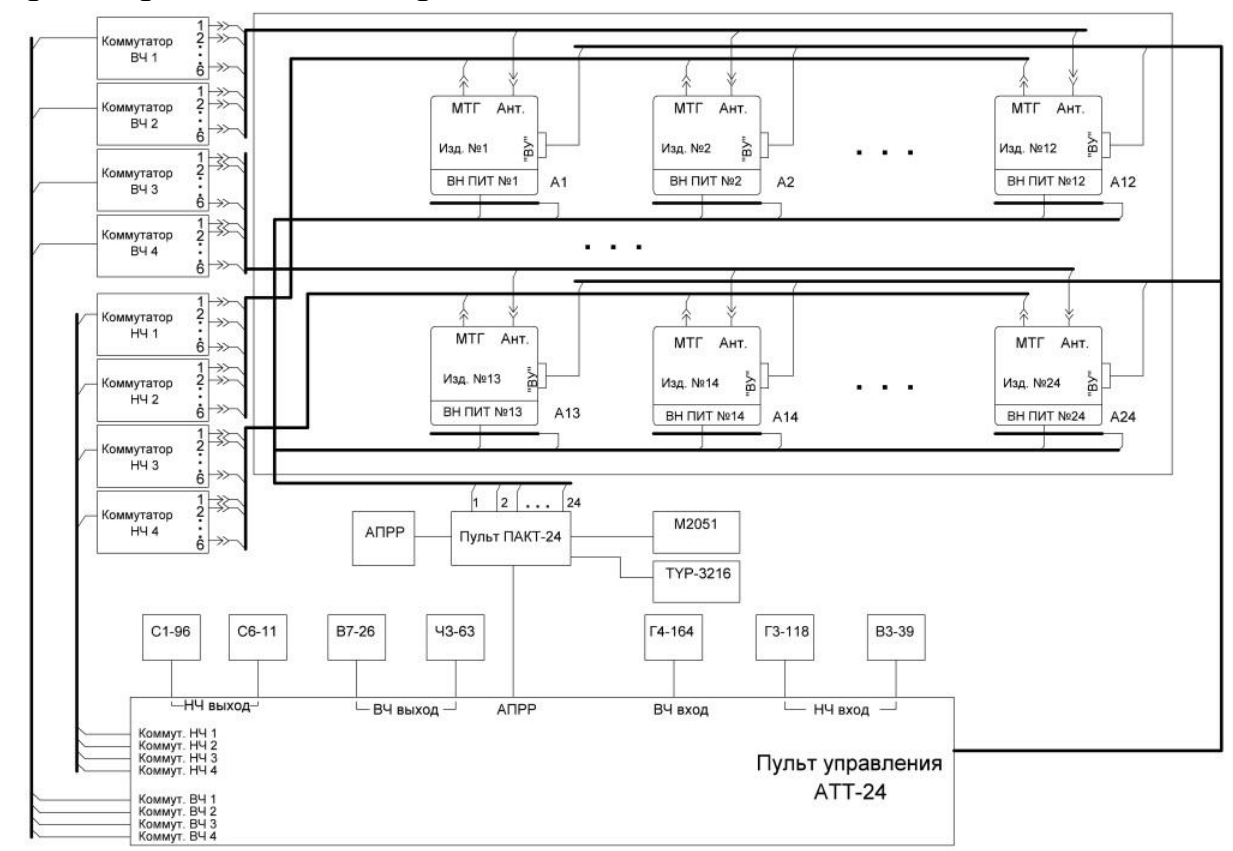

Рис.1.Структурная схема рабочего места проведения технологической тренировки

В состав рабочего места входит ряд специализированных технологических приспособлений, таких как:

- $\quad$ пульт управления технологической тренировки ТT-24

- $\quad$ автомат переключения рода работ АПРР

- $\quad$ пульт автоматизированного контроля тока ПАКТ-24

А так же измерительные приборы, позволяющие измерять основные параметры приемопередатчиков [2].

Управление приборами и процесс измерения осуществляется оператором вручную. Сложность измерения основных параметров приемопередатчиков требует больших временных затрат и высокой квалификации оператора, производящего тренировку.

В настоящее время появились современные приборы, например радиотестер Rohde \& Schwarz CMA180, который объединяет в себе функции этих измерительных приборов. Помимо своей комплексности он имеет возможность управления от компьютера, что позволяет использовать его при создании автоматизированного рабочего места(АРМ).

Структурная схема нового рабочего места представлена на рис.2. 


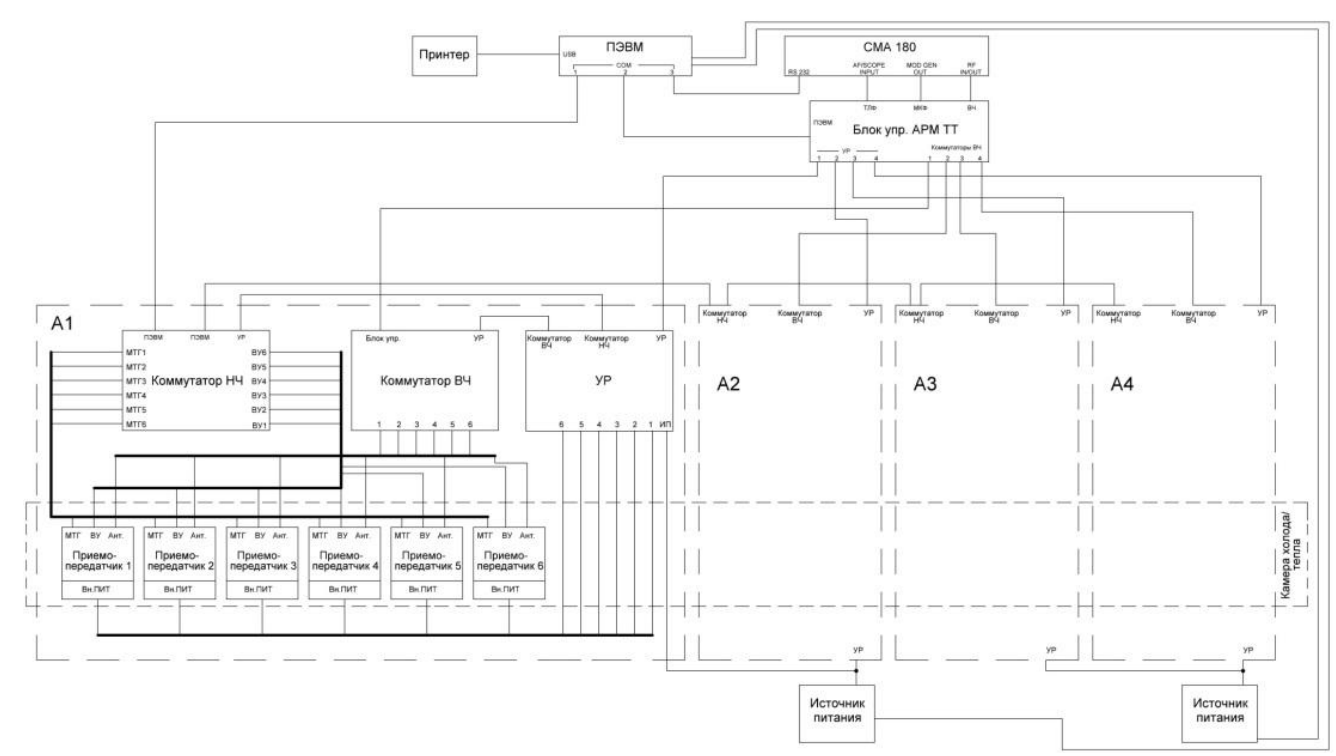

Рис.2.Структурная схема автоматизированного рабочего места

Исполнительная часть АРМ разработана, исходя из требований обеспечения режима технологической тренировки с соотношением времени нахождения изделия в режиме «Приём» к времени нахождения в режиме «Передача» 5:1. Поэтому она разработана секционно и состоит из четырех идентичных секций. В каждой секции тренируются до шести приемопередатчиков.

Основным элементом системы управления АРМ является ПЭВМ. В качестве контрольно измерительного прибора используем радиотестер СМА180. Так же используется набор из технологических приспособлений, таких как коммутаторы ВЧ и НЧ, УР, которые осуществляют подключение 24 приемопередатчиков к этому измерительному прибору.

Основным управляющим устройством всех этих технологических приспособлений является разрабатываемый блок управления.

Он осуществляет: коммутацию тренируемых изделий; обеспечивает необходимый режим технологической тренировки; перевод приемопередатчика в режим прием и передача; распределение питания; выбор для контроля параметров конкретного приемопередатчика.

Таким образом, блок управления позволяет полностью сделать процесс тренировки автоматизированным вплоть до формирования протокола с фиксацией конкретных технических характеристик изделий и с выводом протокола на печать. Поэтому решение задачи создания АРМ ТТ на базе этого блока управления является актуальной, так как будет полностью исключено присутствие человека в процессе тренировки (за исключением установки на тренировку и съема с нее изделий), что позволит не только снизить требования к квалификации обслуживающего персонала, а соответственно снизить трудозатраты, но и повысить объективность получаемых данных, а соответственно и качество выпускаемых изделий.Его главные достоинства: снижение издержек на производстве; одновременная тренировка большого количества изделий, что значительно повышает производительность труда; исключение субъективного фактора: невнимательность человека, его неаккуратность и т.д.; автоматическое отключение изделия при появлении перегрузки, что уменьшает вероятность полного выхода его из строя; сопряжение с компьютером, что обеспечивает получение более структурированной информации и возможность обработки данных с любого компьютера. 
Структурная схема блока управления АРМ ТТ представлена на рис.3. Основным узлом этого блока является плата управления, так же имеется плата измерителя токов, внутренний источник питания, каналы подключения клавиатуры и индикатора.

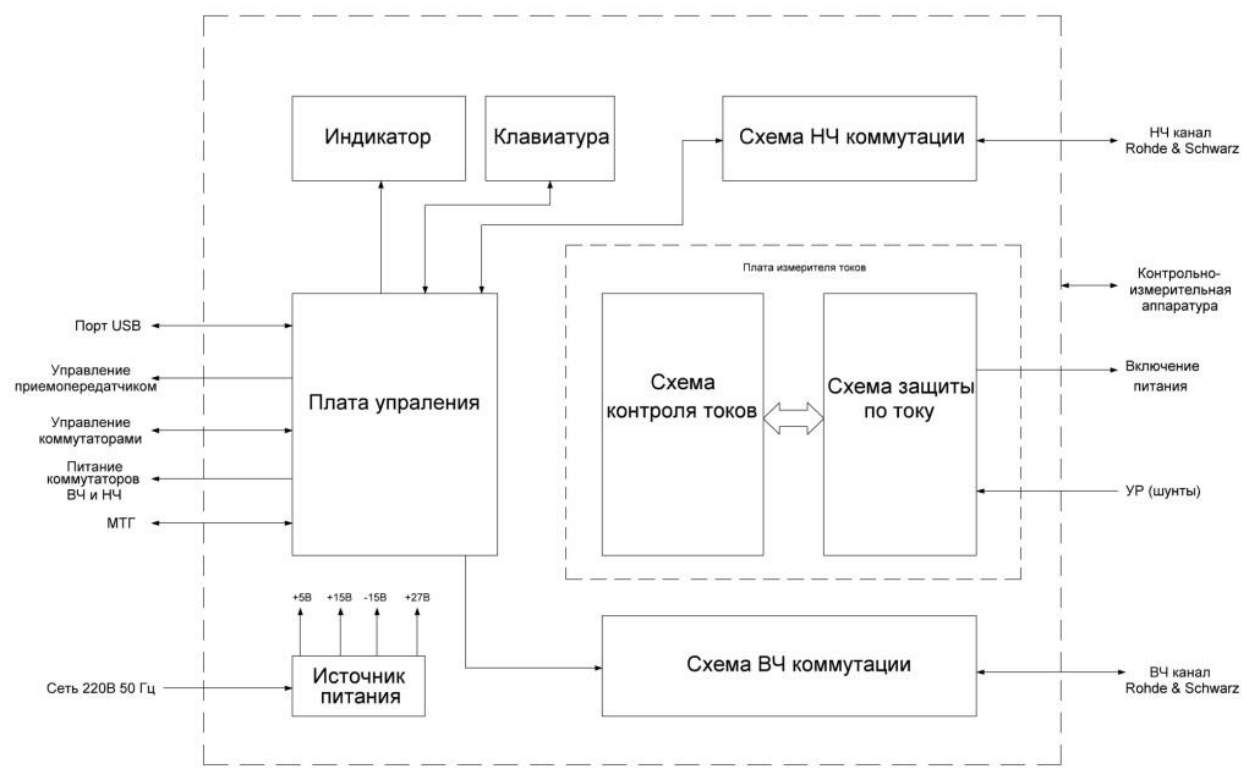

Рис.3. Структурная схема блока управления АРМ TT

Его функциональная схема приведена на рис.4. Она состоит из микроконтроллера, канала измерения токов и напряжения, канала управления приемопередатчиками, канала управления ВЧ и НЧ сигналами.

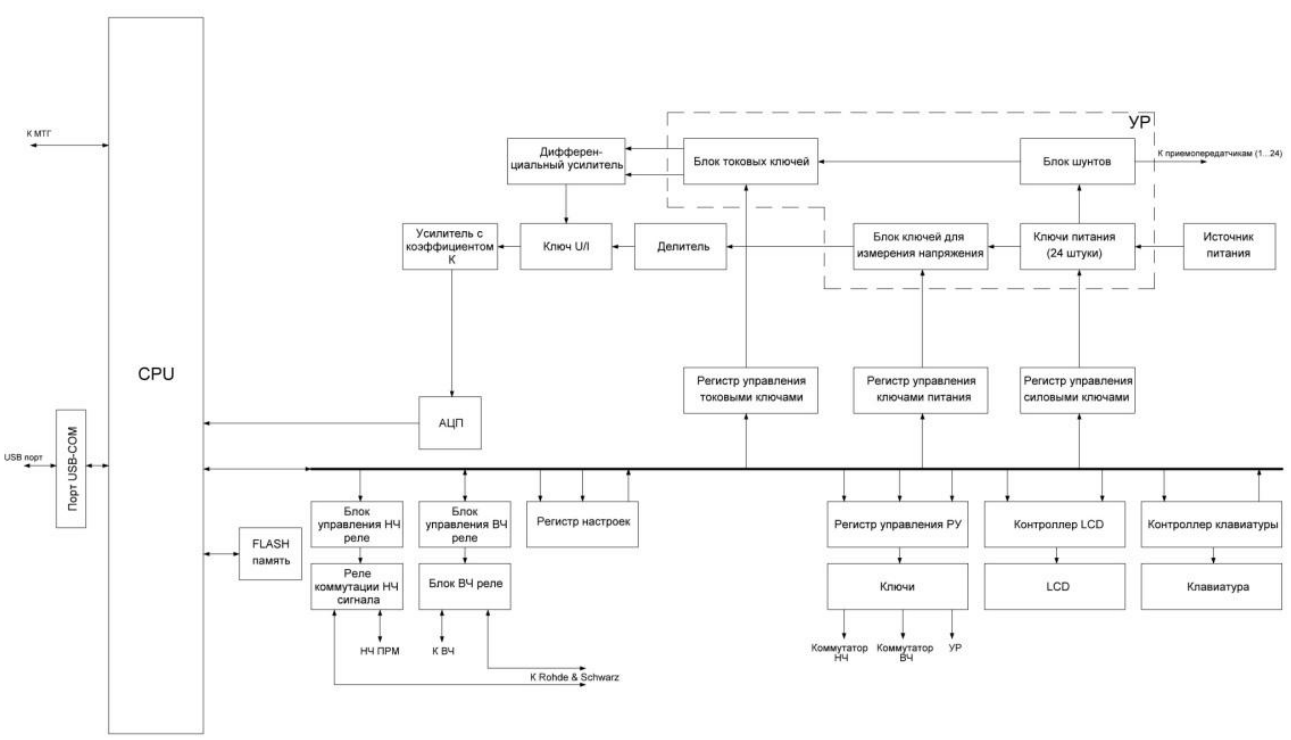

Рис.4. Функииональная схема блока управления АРМ ТT

Таким образом, был разработан блок управления автоматизированного рабочего места технологической тренировки систем связи на основе УКВ радиостанций, который позволяет создать рабочее место технологической тренировки полностью автоматизированным.

\section{$* * *$}

1. Технология производства радиоэлектронной аппаратуры, В.П. Гусев, Москва, 1961.

2. Электротехнический справочник, Т. 2, под ред. В. Г. Герасимова, Издательство МЭИ, Москва, 2003. 